\title{
Deep brain stimulation versus anterior capsulotomy for obsessive-compulsive disorder: a review of the literature
}

\author{
Joshua Pepper, MBBS, ${ }^{1}$ Marwan Hariz, MD, PhD, ${ }^{1,2}$ and Ludvic Zrinzo, MD, PhD, FRCS1,3 \\ ${ }^{1}$ Unit of Functional Neurosurgery, University College London Institute of Neurology, Queen Square; ${ }^{3}$ Victor Horsley Department \\ of Neurosurgery, National Hospital for Neurology and Neurosurgery, Queen Square, London, United Kingdom; and ${ }^{2}$ Department \\ of Clinical Neuroscience, Umeå University, Umeå, Sweden
}

\begin{abstract}
Obsessive-compulsive disorder $(\mathrm{OCD})$ is a chronic and debilitating psychiatric condition. Traditionally, anterior capsulotomy (AC) was an established procedure for treatment of patients with refractory OCD. Over recent decades, deep brain stimulation (DBS) has gained popularity. In this paper the authors review the published literature and compare the outcome of AC and DBS targeting of the area of the ventral capsule/ventral striatum (VC/VS) and nucleus accumbens (NAcc).

Patients in published cases were grouped according to whether they received AC or DBS and according to their preoperative scores on the Yale-Brown Obsessive-Compulsive Scale (YBOCS), and then separated according to outcome measures: remission (YBOCS score $<8$ ); response ( $\geq 35 \%$ improvement in YBOCS score); nonresponse $(<35 \%$ improvement in YBOCS score); and unfavorable (i.e., worsening of the baseline YBOCS score).

Twenty studies were identified reporting on 170 patients; 62 patients underwent DBS of the VC/VS or the NAcc (mean age 38 years, follow-up 19 months, baseline YBOCS score of 33), and 108 patients underwent AC (mean age 36 years, follow-up 61 months, baseline YBOCS score of 30). In patients treated with DBS there was a $40 \%$ decrease in YBOCS score, compared with a $51 \%$ decrease for those who underwent AC $(p=0.004)$. Patients who underwent AC were $9 \%$ more likely to go into remission than patients treated with DBS $(p=0.02)$. No difference in complication rates was noted.

Anterior capsulotomy is an efficient procedure for refractory OCD. Deep brain stimulation in the VC/VS and NAcc area is an emerging and promising therapy. The current popularity of DBS over ablative surgery for OCD is not due to nonefficacy of AC, but possibly because DBS is perceived as more acceptable by clinicians and patients.

http://thejns.org/doi/abs/10.3171/2014.11.JNS132618
\end{abstract}

KEY WORDS deep brain stimulation; anterior capsulotomy; obsessive-compulsive disorder; psychosurgery; functional neurosurgery

$\mathrm{O}$ BSESSIVE-compulsive disorder (OCD) affects approximately $2 \%$ of the global population and represents one of the highest global burdens of psychiatric disability. ${ }^{48}$ In the majority of cases OCD is managed successfully with psychiatric treatment. However, a significant minority of patients fail to improve or worsen. ${ }^{10,41}$ Severe refractory OCD carries a vast morbidity ${ }^{27}$ and in a few of the most severe cases neurosurgery has been performed.

Talairach in France first reported anterior capsulotomy
(AC) in 1949. ${ }^{46}$ Leksell in Sweden introduced a more refined stereotactic AC for surgical treatment of various psychiatric disorders in the early 1950s. ${ }^{25}$ Obsessive-compulsive disorder was found to respond favorably. ${ }^{20}$ In parallel, anterior cingulotomy for OCD was introduced in the US and popularized by Ballantine, ${ }^{2}$ whereas $\mathrm{AC}$ remained relatively more prevalent in Europe and elsewhere.

However, the use of untargeted operations in nonselect psychiatric patients during the 1930s-1960s generated public and professional aversion to any ablative neuro-

ABBREVIATIONS AC = anterior capsulotomy; CBT = cognitive behavioral therapy; DBS = deep brain stimulation; ICH = intracranial hemorrhage; $\mathrm{NAcC}=$ nucleus accumbens; OCD = obsessive-compulsive disorder; VC/VS = ventral capsule/ventral striatum; YBOCS = Yale-Brown Obsessive-Compulsive Scale.

ACCOMPANYING EDITORIAL See pp 1026-1027. DOI: 10.3171/2014.9.JNS14925.

SUBMITTED November 26, 2013. ACCEPTED November 11, 2014.

INCLUDE WHEN CITING Published online January 30, 2015; DOI: 10.3171/2014.11.JNS132618.

DISCLOSURE Drs. Hariz and Zrinzo occasionally receive travel expenses and honoraria for invited talks from industry (Medtronic, St Jude). The authors have no other conflicts of interest related to the topics addressed in this study. 
surgery for psychiatric disorders. The emergence of deep brain stimulation (DBS) in the treatment of refractory motor disorders in the late 1980s paved the way to its eventual use in psychiatric illness.

Modern DBS for OCD was pioneered in $1999 .{ }^{30}$ The initial target was the anterior limb of the internal capsule-the very target used for AC. Since then, the target for DBS in this area of the brain has evolved to encompass the ventral capsule/ventral striatum (VC/VS), including the area of the nucleus accumbens (NAcc). ${ }^{9,18}$

On its inception in movement disorder surgery, the chief benefit of DBS over ablative neurosurgery was that bilateral procedures in motor areas of the basal ganglia and thalamus could be performed with less risk of side effects on speech, swallowing, cognition, and balance. However, the rationale for DBS of nonmotor subcortical areas in psychiatric disorders is less clear, other than it is perceived as nonablative and assumed to be reversible and more forgiving than lesions, and therefore more acceptable. Unlike the case of DBS versus ablative surgery in movement disorders, there has been no previous comparison between outcomes of patients with OCD who received DBS in the anterior capsule area and patients who received $\mathrm{AC}$ treatment.

Here, the published literature on surgery of the anterior capsule for OCD is evaluated and the outcomes of patients treated with $\mathrm{AC}$ are compared with those of patients who underwent DBS in the areas of VC/VS and NAcc.

\section{Methods}

Publications on AC or DBS for OCD were obtained from the PubMed database, from proceedings of neurosurgical meetings, and references from relevant papers. The search criteria, used were in accordance with guidelines published in the Cochrane library. ${ }^{6}$ PubMed was searched using a combination of optimal search strategies and the following phrase(s): surg* OR neurosurg* OR psychosurg* OR radiosurg* OR cinguloto* OR capsuloto* OR tractoto* OR leucoto* OR leukoto* OR thalamoto* OR loboto* OR radio-surg* OR radiosurg* OR stereota* OR stereo-ta* OR gamma kni* OR gamma-ra* OR deep brain stimulation OR DBS OR Neurosurgical Procedures/ AND obsessive compuls* OR obsessive-compuls* OR mood disorders OR anxiety disorders.

Included studies required details of baseline characteristics (diagnosis of OCD, neurosurgical procedure conducted, patient age, and scores on the Yale-Brown $\mathrm{Ob}$ sessive-Compulsive Scale [YBOCS]) at surgery and outcome (minimum follow-up time of 12 months, including YBOCS score at follow-up). Whenever possible, duplicate patients were identified and removed.

Moreover, included papers were screened with respect to reported adverse events. Serious adverse events were defined as those that would contribute significantly to morbidity (infection, epilepsy, intracranial hemorrhage $[\mathrm{ICH}])$ or mortality, including suicide within the first 12 months after surgery. Persisting adverse events were defined as new-onset symptoms that persisted for more than 8 weeks postsurgery. These could include headache, dizziness, nausea, sleep disturbance, apathy, disinhibition, oth- er personality changes, and others. Whenever there was uncertainty about an adverse event (i.e., the length of time it lasted, and so on) it was included in the results.

Patients were grouped according to whether they received AC (either by Gamma Knife or radiofrequency) or DBS in the VC/VS area, including the NAcc. Patients were also placed into "severity groups" according to their preoperative YBOCS score: moderate OCD, 16-23; severe $\mathrm{OCD}, 24-31$; and extreme $\mathrm{OCD}, 32-40.15,34$

These groups were separated into outcome measures based on the Christmas criteria. ${ }^{6}$ Remission requires that YBOCS scores drop below 8. Response is defined as 35\% or more improvement in YBOCS score. Nonresponder status is assigned when remission or response criteria are not met. Worse indicates a worsening of the YBOCS score. When individual data were not available, group averages were used.

\section{Statistical Analysis}

The mean values were calculated. The Student t-test was used to compare continuous data. The Fisher exact test using a $2 \times 2$ contingency table was used to compare the outcomes and complication rates in patients who underwent AC or DBS. A p value $<0.05$ was considered statistically significant.

\section{Results}

In total, 20 studies reporting on 170 patients, spanning more than a decade of publications, were identified. Of these, 10 studies included 108 patients with capsulotomy $5,7,8,17,23,26,28,32,37,41$ and 10 included 62 patients who underwent DBS. 1,9,13,14,18,19,21,35,36,47

Table 1 (AC) and Table 2 (DBS) present details of the number of patients in each study, age at surgery, length of follow-up, details of the surgical procedures, and pre- and postoperative YBOCS scores. Also the level of evidence of each surveyed study is indicated: Level I, randomized controlled trials with narrow confidence interval, or systematic review of randomized controlled trials; Level II, individual cohort studies, systematic review of cohort studies, or ecological studies; Level III, case-control studies and systematic review of case-control studies; Level IV, individual case series including poor-quality cohort and case-control studies; and Level IV, expert opinion based on "first principles" or bench science. Table 3 summarizes the baseline characteristics of both patient groups across all studies with pre- and postoperative YBOCS scores. The gender divide was similar and there was no statistical age difference between the 2 groups. However, patients who underwent DBS had significantly worse preoperative YBOCS scores and longer duration of OCD. Patients who underwent $\mathrm{AC}$ were followed up for longer time periods and their mean improvement in YBOCS score was 51\%, compared with $40 \%$ improvement in patients who underwent DBS ( $p=0.004)$.

Figure 1 shows patient outcome (remission, response, nonresponder, and worse) according to surgical modality. Sixty-two percent of patients who underwent AC experienced a clinically significant response (improvement in YBOCS score $\geq 35 \%$ ) compared with $52 \%$ patients who 
TABLE 1. Literature review of patients with $O C D$ who underwent $A C *$

\begin{tabular}{|c|c|c|c|c|c|c|c|}
\hline Authors \& Year & $\begin{array}{c}\text { No. of } \\
\text { Patients }\end{array}$ & $\begin{array}{c}\text { Mean Age } \\
\text { (yrs) }\end{array}$ & $\mathrm{FU}(\mathrm{mos})$ & Procedure & YBOCS Preop & YBOCS Postop & $\begin{array}{l}\text { Level of } \\
\text { Evidence }\end{array}$ \\
\hline Sheehan et al., 2013 & 4 & 38 & 26 & Bilat GKS, 140-160 Gy & 32 & 17 & IV \\
\hline D’Astous et al., 2013† & 19 & 40.8 & 84 & Bilat BL, $20 \times 5-6 \mathrm{~mm}$ & 35 & 24 & IV \\
\hline Kondziolka et al., 2011 & 3 & $37,40,55$ & 42 & Bilat GKS, 140-150 Gy & $34,39,39$ & $24,7,18$ & IV \\
\hline Gouvea et al., 2010 & 1 & 34 & 12 & Bilat GKS, 180 Gy & 37 & 0 & III \\
\hline Lopes et al., 2009 & 5 & 35 & 48 & Bilat GKS, 180 Gy & 32 & 21 & IV \\
\hline Rück et al., 2008 & 24 & 41 & 124 & $\begin{array}{l}\text { Bilat GKS, } 160-200 \mathrm{~Gy} \\
\text { Unilat \& bilat RF, } 12-20 \mathrm{~mm}, 60^{\circ} \mathrm{C}\end{array}$ & 34 & 19 & IV \\
\hline Liu et al., 2008† & 35 & 30 & 36 & Bilat RF, $70-80^{\circ} \mathrm{C}$ & 21 & 4 & IV \\
\hline Oliver et al., 2003† & 10 & 34 & 12 & Bilat RF, $18 \mathrm{~mm}, 75^{\circ} \mathrm{C}$ & 30 & 17 & IV \\
\hline Christensen et al., 2002 & 2 & 18,64 & 40 & Bilat RF, $65-70^{\circ} \mathrm{C}$ & 30,31 & 0,8 & IV \\
\hline Csigó et al., 2010† & 5 & 32 & 24 & Bilat RF & 38 & 18 & III \\
\hline
\end{tabular}

$\mathrm{BL}=$ Bertrand leukotome; FU = follow-up; GKS = Gamma Knife surgery; RF = radiofrequency ablation.

* Average data are shown for studies with $>3$ patients; for studies with $\leq 3$ patients the data are given individually.

$\dagger$ Implies that group rather than individual data were used in analysis of results.

received DBS. However, this difference was not statistically significant. Eleven percent $(n=12)$ of patients who underwent $\mathrm{AC}$ went into remission (YBOCS score $<8$ ) compared with $2 \%(n=1)$ of patients after DBS $(p=0.02)$.

Figure 2 shows patient outcome in both surgical groups according to OCD severity at baseline. There were 35 patients with moderate OCD who underwent AC; of these $63 \%$ showed a clinically significant response. There were no patients with moderate OCD who underwent DBS.

Among 35 patients with severe OCD, 11 underwent DBS and 24 underwent AC. The patients who underwent $\mathrm{AC}$ were $50 \%$ more likely to have a clinically relevant response (including remission) compared with patients treated with DBS $(\mathrm{p}=0.002)$. Ten percent $(\mathrm{n}=2)$ of patients with severe OCD who underwent $\mathrm{AC}$ went into remission, compared with $0 \%$ of patients who underwent DBS (not significant).

One hundred patients were classified as having extreme OCD (YBOCS score of 32-40). A similar rate of clinically significant response was achieved after AC and DBS (49\% vs 52\%, not significant). However, $20 \%(\mathrm{n}=10)$ of
AC patients with extreme OCD went into remission compared with $2 \%(\mathrm{n}=1)$ of DBS patients with extreme OCD $(\mathrm{p}=0.006)$.

\section{Adverse Events}

Table 4 shows reported adverse events according to surgical procedure. There were 2 suicides and 2 symptomatic and 5 asymptomatic ICHs. One patient developed sustained hemiplegia after intracranial bleeding. There was no difference in the rate of serious adverse events between $\mathrm{AC}$ and DBS. Patients who underwent AC were more than $25 \%$ more likely to have clinically significant weight gain $(\mathrm{p}=0.0002)$. Wound infection was $5 \%$ more common after DBS than after AC $(p=0.02)$. Table 5 lists details of all adverse events reported in each surveyed study.

\section{Discussion}

This literature analysis demonstrates that patients with medically intractable OCD were helped by both stereotactic AC and DBS in the VC/VS and NAcc area. Half of

TABLE 2. Literature review of patients with OCD who underwent DBS in VC/VS and NAcc*

\begin{tabular}{lccccccc}
\hline \multicolumn{1}{c}{ Authors \& Year } & $\begin{array}{c}\text { No. of } \\
\text { Patients }\end{array}$ & $\begin{array}{c}\text { Mean Age } \\
\text { (yrs) }\end{array}$ & FU (mos) & Side & $\begin{array}{c}\text { YBOCS } \\
\text { Preop }\end{array}$ & $\begin{array}{c}\text { YBOCS } \\
\text { Postop }\end{array}$ & $\begin{array}{c}\text { Level of } \\
\text { Evidence }\end{array}$ \\
\hline Greenberg et al., 2010 & 21 & 36 & 29 & Bilat & 34 & 21 & III \\
\hline Roh et al., 2012 & 4 & 34 & 24 & Bilat & 37 & 15 & IV \\
\hline Tsai et al., 2012 & 4 & 26 & 15 & Bilat & 36 & 24 & IV \\
\hline Abelson et al., 2005 & 2 & 34,48 & 18 & Bilat & 26,30 & 25,8 & III \\
\hline Goodman et al., 2010 & 1 & 27 & 12 & Bilat & 34 & 4 & III \\
\hline Huff et al., 2010 & 10 & 36 & 12 & Rt & 32 & 25 & III \\
\hline Franzini et al., 2010 & 2 & 33,41 & 26 & Bilat & 38,30 & 22,20 & IV \\
\hline Denys et al., 2010 & 14 & 44 & 21 & Bilat & 34 & 16 & III \\
\hline Guehl et al., 2008† & 3 & $45,46,56$ & 12 & Bilat & $31,25,25$ & $11 \dagger$ & IV \\
\hline Plewnia et al., 2008 & 1 & 51 & 12 & Rt & 32 & 24 & IV \\
\hline
\end{tabular}

* Average data are shown for studies with > 3 patients; for studies with $\leq 3$ patients the data are given individually.

$\dagger$ Indicates best improvement in YBOCS score reported; improvement range in YBOCS in this paper is $35 \%-60 \%$. 
TABLE 3. Summary of baseline characteristics in patients who underwent $D B S$ versus $A C$

\begin{tabular}{lllc}
\hline \multicolumn{1}{c}{ Characteristic } & AC & DBS & p Value \\
\hline No. of patients & 108 & 62 & \\
\hline$\%$ Male & 54 & 52 & NS \\
\hline Mean age in yrs at op (SD) & $36(12)$ & $38(10)$ & NS \\
\hline Duration of OCD in yrs (SD) & $17(9)$ & $23(9)$ & $<0.0001$ \\
\hline Mean FU in mos (SD) & $61(51)$ & $19(9)$ & $<0.0001$ \\
\hline YBOCS preop (SD) & $30(7)$ & $33(4)$ & 0.002 \\
\hline YBOCS postop (SD) & $14(11)$ & $20(7)$ & 0.0002 \\
\hline$\%$ Improvement (SD) & $51(27)$ & $40(17)$ & 0.004 \\
\hline
\end{tabular}

NS = not significant.

those who underwent DBS and almost two-thirds of patients treated with AC were considered to have a clinically significant improvement (Fig. 1), with patients who underwent AC more likely to go into remission when compared with those treated with DBS. The frequency and profile of adverse events between both procedures was similar.

Both stereotactic ablation and DBS in the anterior capsule area appear to disrupt pathological activity mediated by white matter tracts between thalamus and orbitofrontal cortex, and between caudate and lenticular nucleus, which are thought to play a significant role in mediating OCD symptoms. Functional neuroimaging consistently reports hyperactive cortico-striato-thalamo-cortical circuits in patients with OCD. ${ }^{24,49}$ Interestingly, this aberrant activity appears to be significantly reduced in patients successfully treated by medication, ${ }^{3,45}$ cognitive behavioral therapy (CBT), ${ }^{3,43}$ and neurosurgical intervention. ${ }^{29}$ Thus, the anterior capsule area, especially its ventral aspect, is a sensible target for neurosurgery in patients who have severe and otherwise refractory OCD.

In this review we deliberately chose not to include publications in which DBS for OCD targeted areas other than the VC/VS and NAcc area. Similarly, publications on other stereotactic ablative procedures for OCD, such as cingulotomy, subcaudate tractotomy, and limbic leukotomy, were not included in this review. This is despite

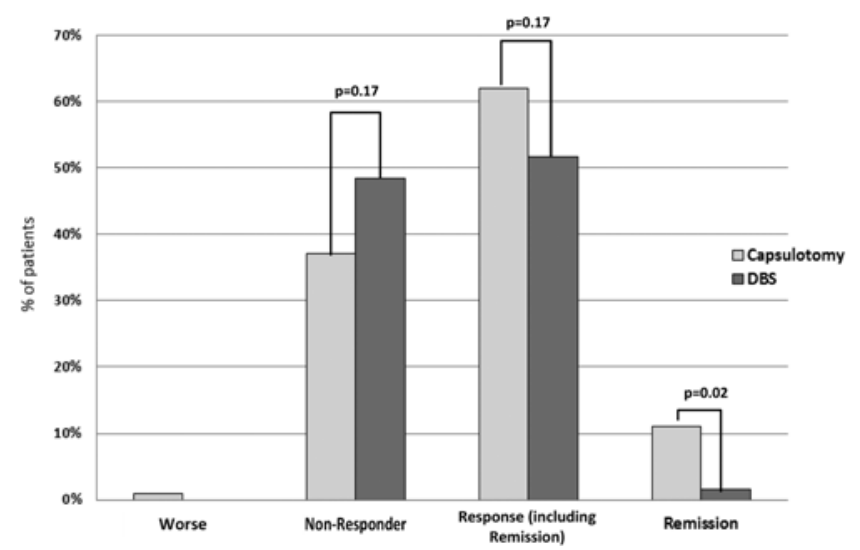

FIG. 1. Bar graph showing the outcome of patients according to surgical modality and according to the predefined 4 levels of response (remission, response, no response, and unfavorable). the fact that procedures such as cingulotomy are still in use, and long-term evaluation performed using established validated scales demonstrates sustained benefit for OCD. ${ }^{42}$ However, it was thought that a fair comparison between the two surgical methods, ablation and stimulation for OCD, would benefit if the anatomical areas of the brain that were targeted were more or less homogeneous between the 2 procedures.

\section{Differences Between Surgical Groups}

This review only considered publications with sufficiently detailed data and in which the validated YBOCS was used for patient evaluation. Therefore, the "old" literature on AC, published before the availability of modern diagnostic criteria and the availability of the YBOCS, was not taken into consideration. Nevertheless, it is not immediately apparent why AC should be more effective than DBS. In that respect there are several issues that need to be analyzed.

\section{Patient Age at Surgery}

Patients treated with DBS were on average 2 years older than those who underwent AC (Table 3), although this difference did not reach statistical significance. Whereas this disparity does not suggest vastly different age categories, it could reflect a longer duration of illness and prolonged failure of other treatments, and thus a worsening of the underlying condition. In patients with OCD treated with CBT, earlier onset of symptoms and longer duration of illness were correlated with poor long-term prognosis. ${ }^{22}$ However, others have stated that the effect size of CBT in OCD did not alter with duration of symptoms or with age difference in adults. Interestingly, the effect size of treatment with CBT was greater in children than in adults. ${ }^{31}$

D'Astous and colleagues reported on 19 patients who underwent mechanical AC in Quebec. ${ }^{8}$ The average age of patients who "responded" to treatment (defined in that study as $>25 \%$ improvement in YBOCS score) was 37.5 years (SD 12.3) compared with 44.4 years (SD 10.2) for patients who did not respond. While the so-called responder group was younger, this difference was not statistically significant. Rück et al. reported on 24 patients who underwent Gamma Knife or radiofrequency AC; 12 experienced a clinically significant response ( $>35 \%$ improvement in YBOCS score) and 12 patients did not respond. ${ }^{37}$ The mean age of responders (43 years, SD 12) was older than the nonresponders (39 years, SD 10). Once again, this difference was not statistically significant.

Extrapolating from different treatment modalities in an adult population, age does not appear to have a strong predictive value in determining outcome after treatment.

\section{Duration of OCD}

Obsessive-compulsive disorder is known to be a chronic and debilitating condition. In published cases, patients who underwent DBS had significantly longer durations of OCD presurgery than patients who underwent AC.

Huff et al. reported 10 patients who underwent DBS of the NAcc for OCD. Only 1 patient had a clinically signifi- 


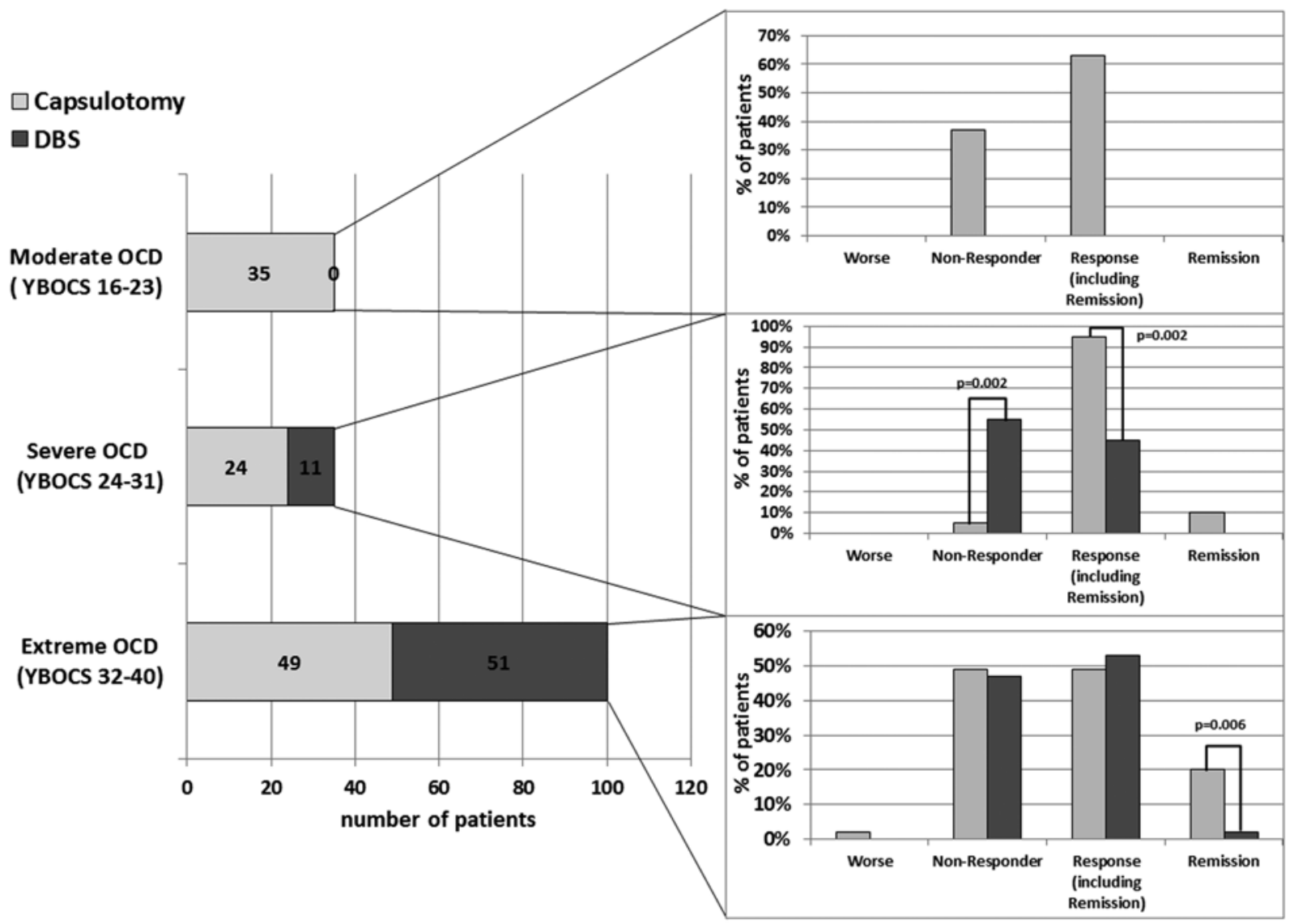

FIG. 2. Bar graphs showing the outcome of patients in both surgical arms according to severity of OCD at baseline.

TABLE 4. Adverse events by category

\begin{tabular}{lccc}
\hline \multicolumn{1}{c}{ Adverse Events } & AC & DBS & p Value \\
\hline Death (related to procedure) & $0 \%$ & $0 \%$ & NS \\
\hline Suicide (w/in 12 mos postop) & $1 \%$ & $2 \%$ & NS \\
\hline Symptomatic ICH & $2 \%$ & $0 \%$ & NS \\
\hline Asymptomatic ICH & $5 \%$ & $3 \%$ & NS \\
\hline Intracranial infection & $0 \%$ & $0 \%$ & NS \\
\hline Residual neurological deficit at 12 mos & $1 \%$ & $0 \%$ & NS \\
\hline Sustained endocrine change & $0 \%$ & $0 \%$ & NS \\
\hline Epilepsy & $1 \%$ & $0 \%$ & NS \\
\hline Persistent postop side effects & $7 \%$ & $5 \%$ & NS \\
\hline Weight gain $>10 \%$ & $29 \%$ & $3 \%$ & 0.0002 \\
\hline Cognitive changes & $7 \%$ & $13 \%$ & $\mathrm{NS}$ \\
\hline Personality change & $6 \%$ & $0 \%$ & $\mathrm{NS}$ \\
\hline Equipment break & $\mathrm{NA}$ & $5 \%$ & $\mathrm{NA}$ \\
\hline Wound infection & $0 \%$ & $5 \%$ & 0.02 \\
\hline
\end{tabular}

NA = not applicable.

* Definitions of events: cognitive change was defined either by self-report, clinical report, or formal neuropsychological testing; epilepsy denotes $>2$ seizures within 12 months or requiring antiepileptic drug therapy for $>6$ weeks after surgery; persistent postoperative side effects were side effects that lasted for $>8$ weeks after surgery, including headache, nausea, vomiting, insomnia, and other symptoms that were not reported as occurring before surgery; and personality change was determined by self-report, relative's report, or formal personality testing. cant response (56\% YBOCS improvement), and the duration of OCD was 34 years. This compares to an average YBOCS improvement of $18 \%$ for the remaining 9 patients, with average disease duration of 20 years. Others noted a similar trend in an ablative series. ${ }^{23}$ Conversely, in another ablative study the average duration of OCD was 12 years for patients who had a clinically relevant response (YBOCS improvement $>25 \%$ ) versus 20 years for patients who did not respond. ${ }^{8}$

These conflicting results from small clinical studies make it difficult to assess whether duration of OCD is a predictor of treatment outcome after neurosurgery. Moreover, without detailed clinical vignettes, it is difficult to know if chronicity represents longer periods of treatment quiescence (and hence neurosurgery would be unnecessary earlier on) or a more medically refractory OCD course.

\section{Severity of $O C D$}

The mean YBOCS scores at surgery were more severe in patients treated with DBS (Table 3). However, it is not entirely clear if severity has a significant impact on treatment response. In patients with OCD who underwent nonneurosurgical treatment, OCD severity did not have an impact on treatment effect with CBT. ${ }^{31,38}$ However, lower symptom severity was associated with greater treatment response to anxiety management.$^{38}$ For patients with OCD 
TABLE 5. Details of adverse events by paper*

\begin{tabular}{|c|c|}
\hline Paper Topic \& Authors & Adverse Events \\
\hline \multicolumn{2}{|l|}{ AC } \\
\hline Sheehan et al., 2013 & No adverse events noted. \\
\hline D’Astous et al., 2013 & $\begin{array}{l}\text { Reoperations (2; small lesion size). Temporary: asymptomatic hemorrhage (3), frontal syndrome (5), urinary incontinence (1), } \\
\text { pneumonia (1), UTI (1), DVT (3). Long-term: hemiplegia (1-periop hemorrhage), cognitive deficit (1). }\end{array}$ \\
\hline Kondziolka et al., 2011 & Patient 2 noted some impulsivity \& perseveration. Neuropsychological test results were normal. \\
\hline Gouvea et al., 2010 & Worsening scores on tests of executive function but no negative impact on life. \\
\hline Csigó et al., 2010 & $\begin{array}{l}\text { Temporary: incontinence (2), periorbital tumescence (2), depressive state (1), anxiety (1), somnolence (1). Long-term: } \\
\text { increased appetite-7-kg weight gain in } 12 \text { mos (2). Improvement of scores in majority of neuropsychological tests. }\end{array}$ \\
\hline Lopes et al., 2009 & $\begin{array}{l}\text { Multiple neurological, psychiatric, \& general medical adverse effects according to the SAFTEE scale listed for patients dur- } \\
\text { ing entire length of FU. Most events short-lived. Long-term: significant weight gain (1), tinnitus (1), facial paresthesia (1). } \\
\text { Temporary: migraines (1), throat swelling (1). No formal neuropsychological testing noted. }\end{array}$ \\
\hline Rück et al., 2008 & $\begin{array}{l}\text { All patients: attempted suicide (6), actual suicide (1)-first suicide attempt in } 4 \text { of } 7 \text { patients. Weight gain: preop weight } 68 \mathrm{~kg} \text {; } \\
\text { postop weight } 76 \mathrm{~kg} \text { at } 1 \text {-yr FU. Long-term mean weight was } 8.1 \mathrm{~kg}(22) \text {. WCST scores ranged from } 41 \text { preop to } 31 \text { postop } \\
\text { (7). } \\
\text { RF: Long-term: sexual disinhibition (1), brain edema (apathy, incontinence, seizures) (1), radiation necrosis (apathy, memory } \\
\text { problems) (1). } \\
\text { GKS: Long-term: severe sexual dysfunction (1), urinary incontinence (1). }\end{array}$ \\
\hline Liu et al., 2008 & $\begin{array}{l}\text { Intracerebral hematoma requiring ventricular drainage (1). Long-term: personality change-apathy/abulia (2). Temporary: } \\
\text { urinary incontinence for 3-5 days (3), transient postop cognitive changes for up to } 10 \text { days (9). }\end{array}$ \\
\hline Oliver et al., 2003 & Temporary: hallucinations (1), seizures (1). Long-term: behavior change (1). No change in neuropsychological test results. \\
\hline Christensen et al., 2002 & Temporary: lethargy (2). No formal neuropsychological testing. \\
\hline \multicolumn{2}{|l|}{ DBS } \\
\hline Greenberg et al., 2010 & $\begin{array}{l}\text { Small intracerebral hematomas both resolved by } 3 \text { mos (2), equipment break (1 lead break, } 1 \text { extension wire break), super- } \\
\text { ficial wound infection (1), depression/suicidal ideation (3), worsening of OCD (3), hypomania (1), problems at home (1). } \\
\text { Cognitive events (verbal perseveration, brief memory flashbacks) (2). No pervasive cognitive decline. }\end{array}$ \\
\hline Tsai et al., 2012 & Allergy to IPG (1). Transient: hypomania (2), vertigo (1), olfactory hallucinations (1). \\
\hline Roh et al., 2012 & Transient: anxiety (2), hypomania (1). \\
\hline Huff et al., 2010 & $\begin{array}{l}\text { No surgical complications noted. Paresthesia that abated (1), suicidal thoughts (1), insomnia (1), headache (1). Results on } \\
\text { tests of cognitive function did not differ. }\end{array}$ \\
\hline Goodman et al., 2010 & $\begin{array}{l}\text { No procedure complications or long-term adverse effects noted. No significant change in neuropsychological test perfor- } \\
\text { mance. }\end{array}$ \\
\hline Franzini et al., 2010 & None noted. \\
\hline Denys et al., 2010 & $\begin{array}{l}\text { Wound infection (1), increased libido (7), micturition problems (2), forgetfulness (5), word-finding difficulty (3). Neuropsycho- } \\
\text { logical test results not available. }\end{array}$ \\
\hline Plewnia et al., 2008 & Wound infection (1). \\
\hline Guehl et al., 2008 & None noted. \\
\hline Abelson et al., 2005 & Electrode break (1), suicide "not linked to surgery" (1). No change in results of neuropsychological testing. \\
\hline
\end{tabular}

DVT = deep vein thrombosis; IPG = implantable pulse generator; SAFTEE = Systematic Assessment for Treatment Emergent Events; UTI = urinary tract infection; WCST $=$ Wisconsin Card Sorting Test.

* Numbers in parentheses indicate number of patients.

who underwent $\mathrm{AC}$, one study found no difference in the presurgery YBOCS scores between patients who responded to surgery and nonresponders. ${ }^{8}$ In contrast, the average presurgery YBOCS scores of nonresponders (YBOCS score $<35 \%$ improvement) at the Karolinska Institute was 35 (SD 3), compared with 32 (SD 3) for patients who had a clinically significant response $(p=0.02)$, suggesting that OCD symptom severity may have a negative predictive value for treatment response. ${ }^{37}$

Moreover, worse OCD severity is also associated with a higher number of comorbidities, particularly generalized anxiety disorder and agoraphobia. ${ }^{11}$ Patients with OCD who have comorbid psychiatric disorders are more likely to have impaired long-term outcome. ${ }^{22}$ Thus, it may not be symptom severity that partly determines treatment response but other associated factors, particularly the number of comorbidities. Conversely, of the 19 patients who underwent $\mathrm{AC}$ for $\mathrm{OCD}$ in Quebec, no difference was found in the number of comorbidities between the socalled responders and nonresponders. ${ }^{8}$

In this review a significant number of patients who underwent AC suffered from moderate OCD (YBOCS score of 16-23); on the other hand, all patients who received DBS belonged to the severe and extreme groups (Fig. 2). 
This may have contributed to the overall better effect of AC compared with DBS. Nevertheless, when patients were analyzed according to presurgery YBOCS scores, those who underwent AC were more likely to have better responses to treatment compared with patients who underwent DBS (Fig. 2).

\section{Follow-Up Duration}

Capsulotomy patients were followed up for much longer time periods than those who underwent DBS (Table 3). Deep brain stimulation modulates the neural circuitry underpinning OCD. Thus, optimizing stimulation settings may take some time, suggesting that even longer follow-up periods might be needed for DBS to ensure maximal gain.

Goodman and colleagues reported on 6 patients who underwent DBS for OCD. Of these, the majority reached maximal treatment response by 6 months, and in 1 patient maximal response was reached at 9 months..$^{14}$ A similar pattern was seen in patients who underwent capsulotomy for OCD. In those who did respond, the largest treatment response was seen within the first 6 months, and this was maintained until the last follow-up.,17,26,28,32 However, Kondziolka et al. recently reported on 3 patients who underwent $\mathrm{AC}$ who continued to experience improvements in YBOCS score up to a maximal follow-up of 55 months. ${ }^{23}$ The published data seem to suggest that, for the most part, response to treatment is established within a relatively short time frame. Disparities in follow-up between the 2 surgical groups probably had little impact on outcome differences. Another issue that needs to be taken into account is the recommended addition of CBT in the postoperative care of patients, whether after DBS or AC. Many reports on surgery for OCD do not clarify this issue. However, 1 study suggested that the addition of CBT after DBS did improve outcome ${ }^{9}$ and, in another study, Gamma Knife AC enabled 1 patient to undergo further psychological treatment with Exposure and Response Prevention. ${ }^{44}$

\section{Surgical Learning Curve}

Surgical learning curves are well documented in many surgical fields. ${ }^{39,40}$ Stereotactic ablative neurosurgery for psychiatric disorders has been performed for more than half a century, ${ }^{25}$ whereas experience with DBS for OCD is just over a decade old. ${ }^{30}$ Greater experience with ablation and the more "standardized" practice of AC may account for some of the reasons why outcomes are better for that procedure. Also, the variability in modes and patterns of stimulation as well as variation in targeting the relatively wide anatomical area encompassing the anterior internal capsule-ventral striatum and NAcc area for $\mathrm{DBS}^{18}$ may all account for the discrepancy in outcome after DBS compared with AC. There is still a learning curve in the practice of DBS for OCD, and this procedure is still considered investigational in many countries. It is interesting to note that the pioneers of DBS for OCD considered it premature for the FDA to grant a humanitarian device exemption for this procedure in $2011 .^{12}$

\section{The YBOCS}

The YBOCS is a validated scoring scale used to de- termine the severity of OCD. ${ }^{15,16}$ It is extremely useful in clinical practice as a means to determine changes over time in the global score, which represents either clinical improvement or deterioration. Moreover, it also allows a direct comparison between different treatment modalities in managing OCD, which would otherwise not be possible.

However, as with many scoring systems, it does not take into consideration aspects of everyday life and quality of life. We appreciate that these dimensions can be difficult to measure and even more cumbersome to compare across different treatment modalities. Some studies have used other scoring systems such as the global assessment of function in an attempt to measure these subjective outcomes. ${ }^{13,18,23,26,28,32,37}$ Older, pre-YBOCS publications on AC for OCD often provided detailed clinical vignettes about whether the patients' functioning had improved; his or her return to work part- or full-time; impact on relationships; and so on..$^{20}$ These old reports provided a wealth of information that was certainly very pertinent to patients in their everyday life after surgery. We chose not to consider these publications in our review because they lacked the (then nonexistent) modern YBOCS, which would make direct comparison with modern DBS publications impossible. Even a qualitative evaluation between DBS publications and old AC papers would have been impossible because modern DBS publications lack the detailed vignettes that some of the old publications contained.

\section{Adverse Events}

The proportion of adverse events that occurred in patients who underwent $\mathrm{AC}$ and those treated with DBS was quite similar; however, there were a few notable differences (Table 4). Capsulotomy patients were more likely to experience clinically significant weight gain. However, because of a noted history of weight gain after AC, papers on this procedure appeared to be more fastidious in noting weight gain as a side effect. Weight was rarely mentioned in DBS publications. Moreover, AC has traditionally been associated with frontal lobe dysfunction such as apathy and disinhibition. However, the published data suggest that the rate of executive dysfunction is greater in DBS patients. It should be noted that publications on DBS often reported on formal tests of cognition and personality, whereas AC publications did so with less frequency. Therefore, it seems likely that this result may simply be a product of underreporting in publications on AC.

Of note, the rate of serious adverse effects (suicide, death, ICH, residual neurological deficit) was low, and it was similar between the 2 groups.

The advantage that DBS has over AC is that, should side effects outweigh benefits, these side effects are theoretically reversible on altering or switching off stimulation. On the other hand, reports of symptom rebound with depleted batteries, and the need for frequent battery replacements and associated high costs are starting to emerge, highlighting potential disadvantages of DBS. ${ }^{48}$ Other drawbacks of DBS compared with AC are the additional risks of infection and equipment breakage. In the surveyed studies, the cumulative rate of infection reported was in line with other DBS publications. ${ }^{4,33}$ 


\section{Limitations of This Review}

In the absence of a head-to-head comparison, this literature review compiles the data available to inform the reader about the respective pros and cons of $\mathrm{AC}$ versus DBS for OCD. However, there are some inherent limitations to our findings due to the very nature and details (or absence thereof) of the reviewed publications.

\section{Grouped Data}

For some of the data analysis, grouped and average data were used as opposed to individual data., ${ }^{7,26,32}$ All grouped data used in this analysis were for patients who underwent AC. This would not have an impact on the average age of patients, the gender split, the length of follow-up, the initial YBOCS score, the improvement in YBOCS score, or the number of adverse effects. This did affect the number of patients in each severity group (moderate, severe, and extreme OCD) and in each response group (remission, response, no response, and unfavorable). It was possible to decipher some of this information. However, patients were not considered to meet response or remission criteria unless clearly stated, and were considered nonresponders if in doubt. It is thus plausible that the number of patients treated with $\mathrm{AC}$ who responded is underrepresented.

\section{Classification of Outcomes}

For example, in the paper by Liu et al. ${ }^{26}$ it is possible to ascertain the number of responders and nonresponders. It is not possible to ascertain the number of patients who went into remission. Because the average improvement in YBOCS score was almost $80 \%$, it seems plausible that a number of these patients would have gone into remission. In this study they were all classified as responders. Thus, from these data, the overall number of patients treated with $\mathrm{AC}$ who went into remission is almost certainly underrepresented.

Even taking into consideration a stringent analysis and interpretation of the available data, this review highlights an important finding: $\mathrm{AC}$ is an effective treatment for refractory OCD. We may safely conclude that the reason that $\mathrm{AC}$ has been and still is underused is not due to its lack of efficacy. Conversely, superiority over AC cannot be the reason for contemporary enthusiasm for DBS in the surgical treatment of OCD-either in terms of efficacy or with regard to side effects and complications. However, DBS does provide more opportunities to study brain circuitry and allows the conduct of sham treatment studies that may provide a stronger evidence base for this surgical therapy. Another advantage is that different parameters (number and site of electrode contacts, frequency, polarity, and intensity) can be tested to provide bespoke optimization for individual patients. However, this can be extremely timeconsuming and challenging. Moreover, at least theoretically, DBS is still considered and perceived as a "reversible" surgery.

\section{Conclusions}

The AC and DBS procedures are effective for refractory OCD. Deep brain stimulation in the ventral anterior capsule and its vicinity is an emerging and promis- ing treatment. None of these therapies is strictly evidence based, and there are no head-to-head comparative studies between these 2 procedures. Also, none of the studies surveyed used evaluation by independent parties who were not involved in selection, surgery, or follow-up of the patients. Hence, an observer bias in reporting results cannot be excluded. However, there is a wealth of historical praxis and modern data pointing to the efficacy of AC. One may safely conclude that the current popularity of DBS over ablative surgery for OCD is not due to clinical superiority over AC, but rather that clinicians and patients find DBS to be more acceptable.

\section{Acknowledgments}

This work was partly funded by the Department of Health National Institute for Health Research Biomedical Research Centres' funding scheme. The Unit of Functional Neurosurgery, UCL Institute of Neurology, is supported by the Sainsbury Monument Trust and The UK Parkinson's Appeal.

\section{References}

1. Abelson JL, Curtis GC, Sagher O, Albucher RC, Harrigan $\mathrm{M}$, Taylor SF, et al: Deep brain stimulation for refractory obsessive-compulsive disorder. Biol Psychiatry 57:510-516, 2005

2. Ballantine HT Jr, Cassidy WL, Flanagan NB, Marino R Jr: Stereotaxic anterior cingulotomy for neuropsychiatric illness and intractable pain. J Neurosurg 26:488-495, 1967

3. Baxter LR Jr, Schwartz JM, Bergman KS, Szuba MP, Guze BH, Mazziotta JC, et al: Caudate glucose metabolic rate changes with both drug and behavior therapy for obsessivecompulsive disorder. Arch Gen Psychiatry 49:681-689, 1992

4. Bhatia R, Dalton A, Richards M, Hopkins C, Aziz T, Nandi $\mathrm{D}$ : The incidence of deep brain stimulator hardware infection: the effect of change in antibiotic prophylaxis regimen and review of the literature. Br J Neurosurg 25:625-631, 2011

5. Christensen DD, Laitinen LV, Schmidt LJ, Hariz MI: Anterior capsulotomy for treatment of refractory obsessivecompulsive disorder: results in a young and an old patient. Stereotact Funct Neurosurg 79:234-244, 2002

6. Christmas DMB, Crombie I, Eljamel S, Fineberg N, MacVicar B, Matthews K, et al: Neurosurgery for obsessive-compulsive disorder, other anxiety disorders and depressive disorders (protocol). Cochrane Database Syst Rev 4:CD005560, 2005

7. Csigó K, Harsányi A, Demeter G, Rajkai C, Németh A, Racsmány M: Long-term follow-up of patients with obsessivecompulsive disorder treated by anterior capsulotomy: a neuropsychological study. J Affect Disord 126:198-205, 2010

8. D'Astous M, Cottin S, Roy M, Picard C, Cantin L: Bilateral stereotactic anterior capsulotomy for obsessive-compulsive disorder: long-term follow-up. J Neurol Neurosurg Psychiatry 84:1208-1213, 2013

9. Denys D, Mantione M, Figee M, van den Munckhof P, Koerselman F, Westenberg H, et al: Deep brain stimulation of the nucleus accumbens for treatment-refractory obsessivecompulsive disorder. Arch Gen Psychiatry 67:1061-1068, 2010

10. Fineberg NA, Gale TM: Evidence-based pharmacotherapy of obsessive-compulsive disorder. Int J Neuropsychopharmacol 8:107-129, 2005

11. Fineberg NA, Hengartner MP, Bergbaum C, Gale T, Rössler 
W, Angst J: Lifetime comorbidity of obsessive-compulsive disorder and sub-threshold obsessive-compulsive symptomatology in the community: impact, prevalence, socio-demographic and clinical characteristics. Int J Psychiatry Clin Pract 17:188-196, 2013

12. Fins JJ, Mayberg HS, Nuttin B, Kubu CS, Galert T, Sturm V, et al: Misuse of the FDA's humanitarian device exemption in deep brain stimulation for obsessive-compulsive disorder. Health Aff (Millwood) 30:302-311, 2011

13. Franzini A, Messina G, Gambini O, Muffatti R, Scarone S, Cordella R, et al: Deep-brain stimulation of the nucleus accumbens in obsessive compulsive disorder: clinical, surgical and electrophysiological considerations in two consecutive patients. Neurol Sci 31:353-359, 2010

14. Goodman WK, Foote KD, Greenberg BD, Ricciuti N, Bauer $\mathrm{R}$, Ward H, et al: Deep brain stimulation for intractable obsessive compulsive disorder: pilot study using a blinded, staggered-onset design. Biol Psychiatry 67:535-542, 2010

15. Goodman WK, Price LH, Rasmussen SA, Mazure C, Delgado P, Heninger GR, et al: The Yale-Brown Obsessive Compulsive Scale. II. Validity. Arch Gen Psychiatry 46:10121016, 1989

16. Goodman WK, Price LH, Rasmussen SA, Mazure C, Fleischmann RL, Hill CL, et al: The Yale-Brown Obsessive Compulsive Scale. I. Development, use, and reliability. Arch Gen Psychiatry 46:1006-1011, 1989

17. Gouvea F, Lopes A, Greenberg B, Canteras M, Taub A, Mathis M, et al: Response to sham and active gamma ventral capsulotomy in otherwise intractable obsessive-compulsive disorder. Stereotact Funct Neurosurg 88:177-182, 2010

18. Greenberg BD, Gabriels LA, Malone DA Jr, Rezai AR, Friehs GM, Okun MS, et al: Deep brain stimulation of the ventral internal capsule/ventral striatum for obsessive-compulsive disorder: worldwide experience. Mol Psychiatry 15:64-79, 2010

19. Guehl D, Benazzouz A, Aouizerate B, Cuny E, Rotgé JY, Rougier A, et al: Neuronal correlates of obsessions in the caudate nucleus. Biol Psychiatry 63:557-562, 2008

20. Herner T: Treatment of mental disorders with frontal stereotaxic thermo-lesions: a follow-up study of 116 cases. Acta Psychiatr Scand 36 (Suppl 158):1-140, 1961

21. Huff W, Lenartz D, Schormann M, Lee SH, Kuhn J, Koulousakis A, et al: Unilateral deep brain stimulation of the nucleus accumbens in patients with treatment-resistant obsessivecompulsive disorder: outcomes after one year. Clin Neurol Neurosurg 112:137-143, 2010

22. Jakubovski E, Diniz JB, Valerio C, Fossaluza V, BelottoSilva C, Gorenstein C, et al: Clinical predictors of long-term outcome in obsessive-compulsive disorder. Depress Anxiety 30:763-772, 2013

23. Kondziolka D, Flickinger JC, Hudak R: Results following gamma knife radiosurgical anterior capsulotomies for obsessive compulsive disorder. Neurosurgery 68:28-33, 2011

24. Kopell BH, Greenberg BD: Anatomy and physiology of the basal ganglia: implications for DBS in psychiatry. Neurosci Biobehav Rev 32:408-422, 2008

25. Leksell L, Herner T, Liden K: Stereotaxic radiosurgery of the brain: report of a case. Kungl Fysiograf Sällsk Lund Förh 25:1-10, 1955

26. Liu K, Zhang H, Liu C, Guan Y, Lang L, Cheng Y, et al: Stereotactic treatment of refractory obsessive compulsive disorder by bilateral capsulotomy with 3 years follow-up. J Clin Neurosci 15:622-629, 2008

27. Lochner C, Mogotsi M, du Toit PL, Kaminer D, Niehaus DJ, Stein DJ: Quality of life in anxiety disorders: a comparison of obsessive-compulsive disorder, social anxiety disorder, and panic disorder. Psychopathology 36:255-262, 2003

28. Lopes AC, Greenberg BD, Norén G, Canteras MM, Busatto
GF, de Mathis ME, et al: Treatment of resistant obsessivecompulsive disorder with ventral capsular/ventral striatal gamma capsulotomy: a pilot prospective study. J Neuropsychiatry Clin Neurosci 21:381-392, 2009

29. Mindus P, Ericson K, Greitz T, Meyerson BA, Nyman H, Sjögren I: Regional cerebral glucose metabolism in anxiety disorders studied with positron emission tomography before and after psychosurgical intervention. A preliminary report. Acta Radiol Suppl 369:444-448, 1986

30. Nuttin B, Cosyns P, Demeulemeester H, Gybels J, Meyerson $\mathrm{B}$ : Electrical stimulation in anterior limbs of internal capsules in patients with obsessive-compulsive disorder. Lancet 354:1526, 1999 (Letter)

31. Olatunji BO, Davis ML, Powers MB, Smits JA: Cognitive-behavioral therapy for obsessive-compulsive disorder: a metaanalysis of treatment outcome and moderators. J Psychiatr Res 47:33-41, 2013

32. Oliver B, Gascón J, Aparicio A, Ayats E, Rodriguez R, Maestro De León JL, et al: Bilateral anterior capsulotomy for refractory obsessive-compulsive disorders. Stereotact Funct Neurosurg 81:90-95, 2003

33. Pepper J, Zrinzo L, Mirza B, Foltynie T, Limousin P, Hariz M: The risk of hardware infection in deep brain stimulation surgery is greater at impulse generator replacement than at the primary procedure. Stereotact Funct Neurosurg 91:5665, 2013

34. Pinto A, Mancebo MC, Eisen JL, Pagano ME, Rasmussen SA: The Brown Longitudinal Obsessive Compulsive Study: clinical features and symptoms of the sample at intake. J Clin Psychiatry 67:703-711, 2006

35. Plewnia C, Schober F, Rilk A, Buchkremer G, Reimold M, Wächter T, et al: Sustained improvement of obsessivecompulsive disorder by deep brain stimulation in a woman with residual schizophrenia. Int J Neuropsychopharmacol 11:1181-1183, 2008

36. Roh D, Chang WS, Chang JW, Kim CH: Long-term followup of deep brain stimulation for refractory obsessive-compulsive disorder. Psychiatry Res 200:1067-1070, 2012

37. Rück C, Karlsson A, Steele JD, Edman G, Meyerson BA, Ericson K, et al: Capsulotomy for obsessive-compulsive disorder: long-term follow-up of 25 patients. Arch Gen Psychiatry 65:914-921, 2008

38. Russell AJ, Jassi A, Fullana MA, Mack H, Johnston K, Heyman I, et al: Cognitive behavior therapy for comorbid obsessive-compulsive disorder in high-functioning autism spectrum disorders: a randomized controlled trial. Depress Anxiety 30:697-708, 2013

39. Scherner M, Madershahian N, Rosenkranz S, Slottosch I, Kuhn E, Langebartels G, et al: Transapical aortic valve implantation: experiences and survival analysis up to three years. J Card Surg 27:653-661, 2012

40. Sharma NL, Papadopoulos A, Lee D, McLoughlin J, Vowler SL, Baumert H, et al: First 500 cases of robotic-assisted laparoscopic radical prostatectomy from a single UK centre: learning curves of two surgeons. BJU Int 108:739-747, 2011

41. Sheehan JP, Patterson G, Schlesinger D, Xu Z: Gamma Knife surgery anterior capsulotomy for severe and refractory obsessive-compulsive disorder. J Neurosurg 119:1112-1118, 2013

42. Sheth SA, Neal J, Tangherlini F, Mian MK, Gentil A, Cosgrove GR, et al: Limbic system surgery for treatment-refractory obsessive-compulsive disorder: a prospective long-term follow-up of 64 patients. J Neurosurg 118:491-497, 2013

43. Skoog G, Skoog I: A 40-year follow-up of patients with obsessive-compulsive disorder. Arch Gen Psychiatry 56:121127, 1999

44. Spofford CM, McLaughlin NC, Penzel F, Rasmussen SA, Greenberg BD: OCD behavior therapy before and after gamma ventral capsulotomy: case report. Neurocase 20:42-45, 2014 
45. Swedo SE, Pietrini P, Leonard HL, Schapiro MB, Rettew DC, Goldberger EL, et al: Cerebral glucose metabolism in childhood-onset obsessive-compulsive disorder. Revisualization during pharmacotherapy. Arch Gen Psychiatry 49:690-694, 1992

46. Talairach J, Hécaen H, David M: Lobotomie préfrontale limitée par électrocoagulation des fibres thalamo-frontales à leur émergence du bras antérieur de la capsule interne. Rev Neurol 83:59, 1949

47. Tsai HC, Chang CH, Pan JI, Hsieh HJ, Tsai ST, Hung HY, et al: Pilot study of deep brain stimulation in refractory obsessive-compulsive disorder ethnic Chinese patients. Psychiatry Clin Neurosci 66:303-312, 2012

48. Vos T, Mathers CD: The burden of mental disorders: a comparison of methods between the Australian burden of disease studies and the Global Burden of Disease study. Bull World Health Organ 78:427-438, 2000

49. Whiteside SP, Port JD, Abramowitz JS: A meta-analysis of functional neuroimaging in obsessive-compulsive disorder. Psychiatry Res 132:69-79, 2004

\section{Author Contributions}

Conception and design: all authors. Acquisition of data: Hariz, Pepper. Analysis and interpretation of data: all authors. Drafting the article: all authors. Critically revising the article: all authors. Reviewed submitted version of manuscript: all authors. Approved the final version of the manuscript on behalf of all authors: Hariz. Statistical analysis: Pepper. Administrative/technical/material support: Hariz, Zrinzo. Study supervision: Hariz, Zrinzo.

\section{Supplemental Information}

Previous Presentation

Portions of this work were presented in abstract form at the XXth biennial meeting of the European Society for Stereotactic and Functional Neurosurgery, in Cascais, Portugal, on September 28, 2012.

\section{Correspondence}

Marwan Hariz, Unit of Functional Neurosurgery, Institute of Neurology, Box 146, Queen Square, London WC1N 3BG, United Kingdom.email:m.hariz@ucl.ac.uk. 